\title{
Pilot plant long-term test of particulate matter removal from the air stream emerging from granulated fertilizers production (stationary source)
}

\author{
V. Brummer, D. Jecha, P. Lestinsky, P. Skryja \& I. Hudak \\ Institute of Process and Environmental Engineering, \\ Brno University of Technology, Czech Republic
}

\begin{abstract}
In this paper, the results of the 34 day test of particulate matter (PM) removal from air stream emerging from granulated fertilizers production (NPK and mixed ammonium sulphate fertilizers) are presented. Operators of the plant wanted to replace older wet scrubber preferably with filter bags which can provide waste less operation of the technology, because separated PM can be reintroduced to the production. Because of the assumption of the sticky and problematic deposits formation on the filter bags that could increase excessively the pressure loss, test on the pilot unit with 15 filter bags with pulse-jet bags cleaning was carried out. During the test, various technological conditions were tested. Temperatures, stream humidity, pressure loss of bags and inlet and outlet PM concentrations were monitored. It was found that dry cleaning of this air stream is problematic as expected, but feasible. Filter bags were absorbing considerable amounts of water from the dust stream (fertilizers are granulated by steam and water). This fact leads to hard removable deposit formation and increased pressure loss, but if the stream was preheated by a small natural gas burner, the deposition creation was reduced. According to results of the long term test, recommendations for the technological conditions for full scale bag filter were provided for given type of technology and production.
\end{abstract}

Keywords: particulate matter, PM, fertilizer, long-term test, operating conditions, pilot plant, case study, dedust, bag filter. 


\section{Introduction}

Particulate matter (PM) gets into the air by both natural and anthropogenic activities. Traffic is the major anthropogenic source of PM releasing road dust, particles from tires and brake pads, etc. Other anthropogenic sources of PM are emerging from industrial plants, agriculture activities, construction sites, mines and so on, and some of them can be prevented or at least reduced by secondary measures [1].

The negative effects of both fractions of PM - PM 2.5 and PM 10.0 on the human health are already known and well described [1-4]. PM poses more health risk when comparing to common air pollutants like carbon monoxide and even ground level ozone [1] created by photochemical oxidation reactions between nitrogen oxides $\left(\mathrm{NO}_{\mathrm{x}}\right)$ and volatile organic compounds (VOC).

In general, less the particle diameter of PM is, the longer lifetime it has and the greater travel distance it is capable of. Also, smaller particles can penetrate deeper and more frequently into the respiratory system. The biggest negative impact on human health has been observed by the particles with diameter $10 \mu \mathrm{m}$ and less. The particles with diameter less than $5 \mu \mathrm{m}$, can penetrate even into the bloodstream causing additional health complications [1].

Main respiratory system effects associated with PM exposure are decreased lung function due to inflammatory reactions and oxidative stress created in exposed lung cells [2], irritation, coughing and problematic breathing [1]. There are also others unwanted cardiopulmonary effects associated with PM like increased heart rate, decreased heart rate variability, increase in deaths and hospital admissions and possible onset of myocardial infarction [3].

This is of course related to financial and non-financial welfare losses and a significant part of gross domestic product (GDP) is lost, due to adverse PM effects. It is the reason to apply measures focusing on the reduction of emissions in terms of very stringent PM emission limits for polluting industries [1].

Industrial PM emission can be mostly well treated. There are a several possible ways for particulate matter (PM) mitigation emerging form stationary industrial sources. Sometimes only single step cleaning is needed, but many times it is necessary to clean air waste stream with subsequently placed devices, where first step significantly lowers the PM concentration (for example cyclones) and second step lowers the PM concentration even further to meet legislation limits for stationary source.

Filtering elements such as fabric or rigid bag filters (baghouses) are providing very high PM removal efficiencies [4]. Even $99.99 \%$ in terms of efficiency can be achieved [5]. This is the reason, why they are used in industry for dust treatment so frequently [4-7]. The limitation in filter applications lies in the maximum allowable temperature given by used material of the filter bag or candle $[4,6]$. Temperature upper limit for natural fibres is about $90^{\circ} \mathrm{C}$ and fabrics made from glass and synthetic fibres are usable up to $230-260^{\circ} \mathrm{C}$ during continuous operation - PAN $\left(125^{\circ} \mathrm{C}\right)$, PES $\left(140^{\circ} \mathrm{C}\right)$, PPS $\left(180^{\circ} \mathrm{C}\right)$, PI $\left(240^{\circ} \mathrm{C}\right)$, glass $\left(260^{\circ} \mathrm{C}\right)$ [4]. Fabric filters are made from the flexible material, so this makes them less susceptible to 
thermal shocks, rough handling and excessive temperature, which can lead to premature material damage [6].

The industrial filter units are operated usually at the constant flow and as the differential pressure on filter material $(\Delta \mathrm{P})$ is increasing due to particles deposition on the filter bags forming cake, the downstream blower must be present for pressure compensation $[5,8]$.

When the filtration starts, dust particles are being captured on the filter material forming the cake, which properties depends on particle size distribution and particle shape which also play an role on the cake structure and detachment [9]. The developed cake is often fragile [9]. The cake properties as well as increase of $\Delta \mathrm{P}$ further depend on many factors like filtration velocity, dust concentration [10], permeability of the filtering elements [6], types and surface treatment of filter media, operating conditions, gas and dust properties, and equipment design [11].

Filtration velocity is one of the variables that most affects cake porosity - cake porosity decreases as filtration velocity increases [9]. Dust concentration has small influence on filtration operation at constant filtration velocity. Denser cakes are created at low dust concentration. On the other hand, the filtration velocity has a more pronounced effect on the cake density and the specific cake resistance comparing to dust concentration. When there is a rise of filtration velocity and dust concentration remains constant (which shortens filtration times), also rise of specific resistance, density [10] and also mechanical stability [11] of filter cake can be expected. Cake structure and the possibility of its detachment is dependent on particle size distribution and particle shape [9].

The lower the permeability of the filtering elements is, the higher specific cake resistance coefficients can be observed [6].

The reverse-flow pulse jet cleaning is most commonly used for regeneration of filter elements and detachment of the filter cake $[8,9,12]$. The short bursts of high-pressure backpulse air with pressure of (3-7 bar) [8] are injected directly into the opening of the bags (possibly through the Venturi) in the opposite direction of the normal operating flow of the gas [12]. Effect of pulse-jet is affected by filtration velocity, initial pressure, pulse duration, compressed air tank volume, placement of the injection nozzle and the nozzle diameter [8]. By use of pulse jet pulse, part of the cake is detached, which leads to decrease of $\Delta \mathrm{P}$. This cleaning is commonly uneven - "patchy" leaving un-detached part of the cake with different height on different places of the filter element [13].

Among the researchers that are dealing with dust filtration is a consensus about the fact that within the experiments using commercial filters, the operating conditions and device setup should be as close as possible to expected full-scale planned installation $[4,8,9]$.

Results that originate exclusively from pilot test equipment incorporating only few bags (often only one), may provide very different operating characteristics to real industrial dust collectors [8] so experimental setup that is under very similar or same operating conditions to industrial installations is therefore clearly valuable [9].

Also there is a demand for prediction of the long-term performance and service life of the filter elements using as short laboratory tests as possible. Also some 
countries developed standards for testing of filter media, for example: VDI/DIN 3926 "Testing of cleanable filter media" in Germany [14]; ASTM D 6830-02 "Standard test method for characterizing the pressure drop and filtration performance of cleanable filter media" in the US [15]; GB 12625 "Technical requirements of fabric and bag for bag filter" in China [16] and JIS Z 8909-1 "Testing methods of filter media for dust collection" in Japan [17] and more recent international standard ISO11057 "Air quality - test method for filtration characterization of cleanable filter media" [18] combining above mentioned national standards. Service life of the filter media lies in the range of 2 to 4 years, depending on the particular application, which corresponds to 200-400 thousands of cleaning cycles [19].

To predict long term behaviour of the filter media, hundreds of the cleaning cycles are definitely not enough. The filter degradation could be accelerated in the process called "ageing" or "seasoning" using rapid pulse cleaning. Pulse-jet cleaning is a source of stress for the filter material and $5 \mathrm{~s}$ filtration cycle time is recommended by national standards in order to shorten the aging time period [13, 19]. After several thousands of cleaning cycles, the particles on the filter become more difficult to detach [19] and pressure air pulses could affect downstream particle emission when used over long periods [13].

However, it would be preferable to monitor the performance of an industrial filter bags dust collector over a long period instead of using ageing techniques, to get truly representative results, as we tried to achieve in ours industrial case study.

\section{Materials and methods}

\subsection{Current state of technology for the production of granulated fertilizers}

In manufacturing facility, mixed granulated fertilizers are produced by mixing, granulating, drying and subsequent cooling of individual fertilizer components. The design production capacity is $20 \mathrm{t} / \mathrm{h}$.

Granular fertilizer is prepared from loose raw material from the warehouse in the desired amounts and ratios transported by conveyor into a blender, where it will form a perfect mixture of components. To the mixture, portions of the granular product, which do not meet the particle size requirement for the product, returning by transport pathways along with dusty shares of cyclones are added.

This mixture is subsequently granulated in two heating steam granulators. The mixture is then transported by the conveyor into a rotary co-current dryer, wherein the granulated mixture is dried.

Drying takes place co-currently, the drying medium is a flue gas produced by combustion of natural gas $(\mathrm{NG})$ in a burner. Flue gas temperature is regulated in the desired range. Drying is regulated according to the desired temperature for each dried granulate. Flue gas from the dryer is carried through a battery of cyclones by suction created by the blower. New pipeline branch was created for pilot unit (source of dust gas) downstream a cyclones battery and a blower.

The cyclone battery includes 8 identical cyclones. The flow of dust stream discharged from the rotary dryer is split into battery. Pipe branch, which is 
equipped with regulation flap, is located before the cyclones. In this pipeline the air from the hall is sucked and thus the required temperature in the rotary drier is maintained. Due to poor regulation of the gas burner is not possible to regulate the temperature in the dryer using a burner. Temperature in the rotary drier is controlled by opening-closing the flap and amount of air sucked from the hall. By described procedure, the PM removal efficiency up to $90 \%$ is achieved in cyclones.

Dust stream from dryer proceeds through the cyclones and the blower to a wet scrubber. The wet scrubber is composed of a trickle column and a droplet separator. Mechanical state of the wet scrubber is not good and management is considering to exchange it either by a new wet scrubber or dry gas cleaning using textile filter bags.

The results of paper are used to help the implementation of the full-scale filtration unit for dust stream from the rotary dryer based on of the long term pilot test.

\subsection{Pilot unit}

The pilot test lasted for 34 days, in which several technical measurements were performed. Pilot unit for PM removal is dimensioned for treatment of $1000 \mathrm{~m}^{3} / \mathrm{h}$ of waste gas (flue gas) at max. temperature of $250^{\circ} \mathrm{C}$ and the suction up to $10 \mathrm{kPa}$.

The construction of designed experimental unit is specific in many aspects. The most important feature is the ability of easy transportation of experimental unit and its installation directly in the industry. For this reason, the entire unit is autonomous entity and excluding power connection and pressurized air supply is entirely self-sufficient. From a structural point of view, unit is divided into several parts. Visualization of basic pilot unit parts can be seen in Figure 1.

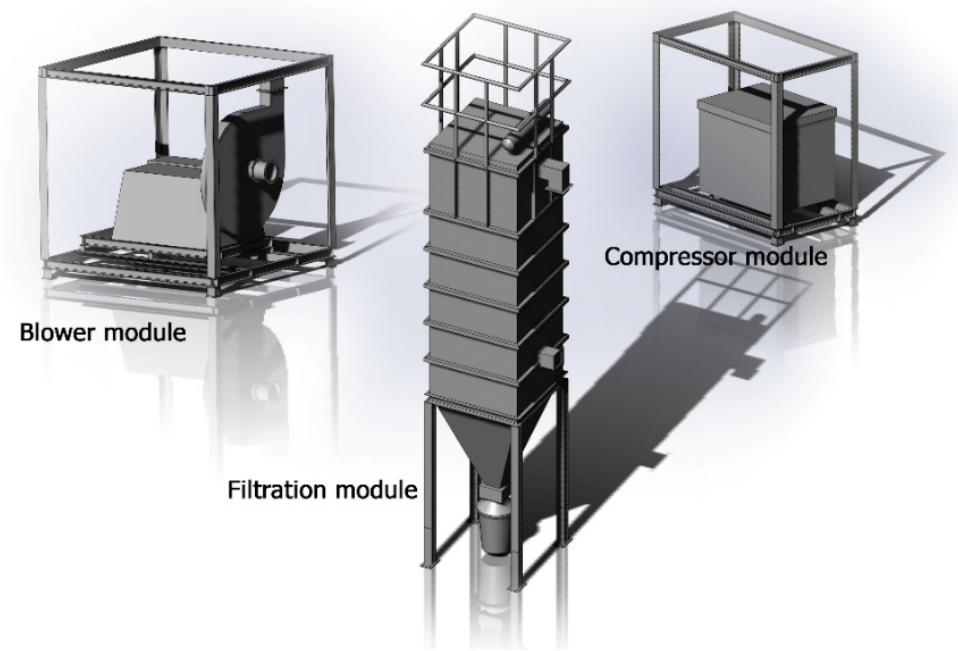

Figure 1: Visualization of the experimental pilot unit. 


\subsection{Filtration module and bag filters}

The filtration module consists of filter construction, a discharge hopper and support structure. On the filter is possible to test PM filtration, optionally deNO or removal of $\mathrm{PCDD} / \mathrm{F}$ by filtration or catalytic filtration. The filter itself contains 15 filter sleeves (Gutsche AR055AR15S1.350) with a diameter of $152 \mathrm{~mm}$ and a length of $2500 \mathrm{~mm}$. Total filtration area is approx. $18 \mathrm{~m}^{2}$, corresponding to the filtration rate of $0.92 \mathrm{~m}^{3} /\left(\mathrm{m}^{2} \mathrm{~min}\right)$ for real gas flow rate $1000 \mathrm{~m}^{3} / \mathrm{h}$. Regeneration of filter bags is performed using pressure jet pulses by compressed air with pressure 5 or 6 bar (the desired pressure of air can be set).

The total pressure drop of the filter was considered $3.0 \mathrm{kPa}$ at maximum load the filter. The construction of the filter creates a pressure drop of approximately $0.1-0.2 \mathrm{kPa}$. Pulses of compressed air can be activated based on the pressure loss threshold or a fixed time cycle. The dust layer is removed during the pulse, thereby ensuring decrease of pressure loss of filtration bags.

Filter module is controlled by software "Control Web", which allows to monitor process parameters such as temperature and pressure at various points of the unit, to control pulse regeneration of filter bags and propulsion (the blower) and compressor module. Further the heating of the discharge hopper can be turned on/off, all measured data are saved in real time to external files and it is possible to track trends and individual parameters. Flow sheet of the filtration unit with measured and controlled variables is shown in Figure 2.

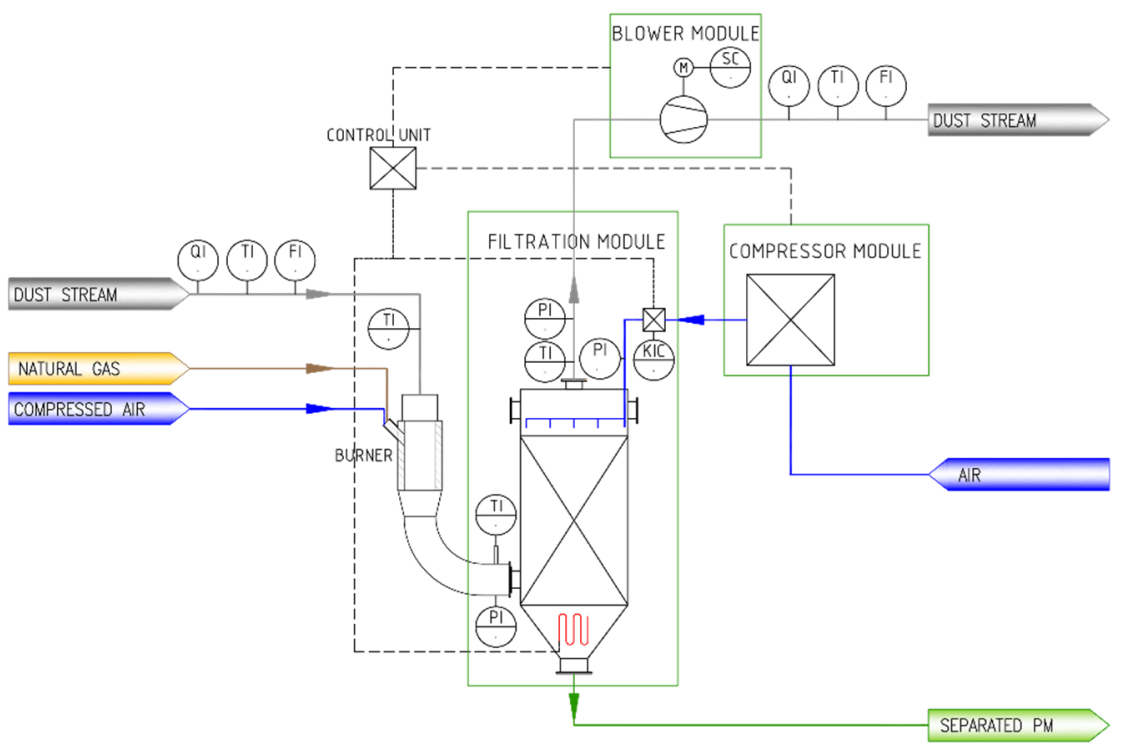

Figure 2: Flow sheet of the filtration unit. 


\subsection{Burner}

For heating of the dust stream, which is collected downstream of the blower, the natural gas burner with approximate output of $18.5 \mathrm{kPa}$ has been incorporated into the piping before the filtration unit. The burner was burning natural gas, which was supplied at $18 \mathrm{kPa}$ with compressed air at a pressure of 5 bar. Heat applied to the dust stream replaced the heat loss of dust stream created before it enters the filtration unit and warmed it even more, thereby achieving greater difference between the current temperature of the stream and dew point of the stream.

\subsection{Measured parameters}

Following parameters were monitored on filtration unit: inlet temperature (before the burner), inlet temperature (after the burner), outlet temperature, inlet pressure (after the burner), outlet pressure, blower rpm (downstream the filtration unit), activation of discharge hopper heating, period of filter regeneration (pressure jet pulses), see Figure 2. Other monitored parameters of the dust stream at inlet and outlet of the filtration unit, such as temperature, humidity and gas velocity were measured manually. Following waste gas parameters were further analysed several times during the long term test: outlet and inlet $\mathrm{PM}$ concentrations and gaseous substances $\left(\mathrm{O}_{2}, \mathrm{CO}, \mathrm{CO}_{2}, \mathrm{SO}_{2}, \mathrm{NO}_{\mathrm{x}}, \mathrm{HCl}\right.$ and $\left.\mathrm{HF}\right)$.

\section{Results and discussion}

Based on the results of measurements and analyses, recommendations to improve the current state and recommendations for the implementation of the future fullscale filtration unit were suggested. The test was performed in real industrial plant. Production of fertilizers followed the normal monthly production plan. During the test, there were frequent outages of technology that could not be controlled or reduced. During the test, the following fertilizer types were processed: granular ammonium sulphate (GR-SA) - approximately $70 \%$ of the production time; fertilizers containing nitrogen, phosphorus and potassium (NPK) - various types, some containing sulphur - about $30 \%$ of production time.

Table 1 shows calculated water concentration in the inlet and the outlet gas, gas velocity and real flow, PM inlet and outlet concentration and calculated PM removal efficiency. Observed PM removal efficiency was on the expected high level about $94-99 \%$. Humidity of the inlet and outlet gas was measured, due to the fact that fertilizers were granulated by water and steam and water capture by filter material with negative impact on deposits and $\Delta \mathrm{P}$ was anticipated. As can be seen on Table 1, inlet water concentration is sometimes quite high and filter material captured $10-40 \mathrm{~g} / \mathrm{kg}$ of dry gas from the gas stream. The blower rpm were adjusted periodically to get real gas flow close to $1000 \mathrm{~m}^{3} / \mathrm{h}$. Pulse pressure was 5 bar until day 30 , after that was changed to 6 bar.

The following figures shows only selected parts of measurements. The unit was started-up without heating of the gas stream during the manufacture of GR-SA. 
Table 1: Measured and calculated parameters.

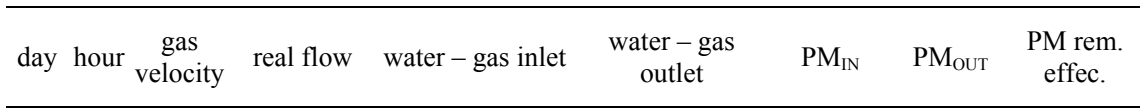

(d) $\quad(\mathrm{h}) \quad(\mathrm{m} / \mathrm{s}) \quad\left(\mathrm{m}^{3} / \mathrm{h}\right) \quad(\mathrm{g} / \mathrm{kg}$ of dry gas $)(\mathrm{g} / \mathrm{kg}$ of dry gas $) \quad\left(\mathrm{mg} / \mathrm{m}^{3}\right) \quad\left(\mathrm{mg} / \mathrm{m}^{3}\right) \quad(\%)$

\begin{tabular}{ccccccccc}
\hline 1 & 0 & 8.7 & 984 & 41.43 & 33.42 & 94.2 & 0.1 & 98.89 \\
\hline 4 & 72 & - & - & 36.85 & - & - & - & - \\
\hline 5 & 96 & - & - & 27.25 & - & - & - & - \\
\hline 6 & 120 & - & - & 77.99 & - & - & - & - \\
\hline 7 & 144 & - & - & $110.27 ; 44.31$ & - & - & - & - \\
\hline 8 & 168 & 8.5 & 961 & 45.57 & 34.14 & - & - & - \\
\hline 9 & 192 & - & - & 55.33 & - & - & - & - \\
\hline 10 & 216 & - & - & $42.60 ; 61.34$ & - & - & - & - \\
\hline 11 & 240 & - & - & 51.35 & - & - & - & - \\
\hline 12 & 264 & - & - & 60.45 & - & - & - & - \\
\hline 15 & 336 & 10 & 1131 & 123.42 & - & 132.0 & 8.0 & 93.94 \\
\hline 16 & 360 & - & - & 159.47 & - & - & - & - \\
\hline 22 & 504 & 11.2 & 1267 & 66.58 & - & - & - & - \\
\hline 29 & 672 & 14,12 & $1583 ; 1357$ & $79.57 ; 113.16$ & $49.64 ; 74.95$ & 94.2 & 4.2 & 95.54 \\
\hline
\end{tabular}

The pressure drop during 4 days gradually increased to $0.65 \mathrm{kPa}$. In the next days, the stream was heated by the burner, see Figure 3 .

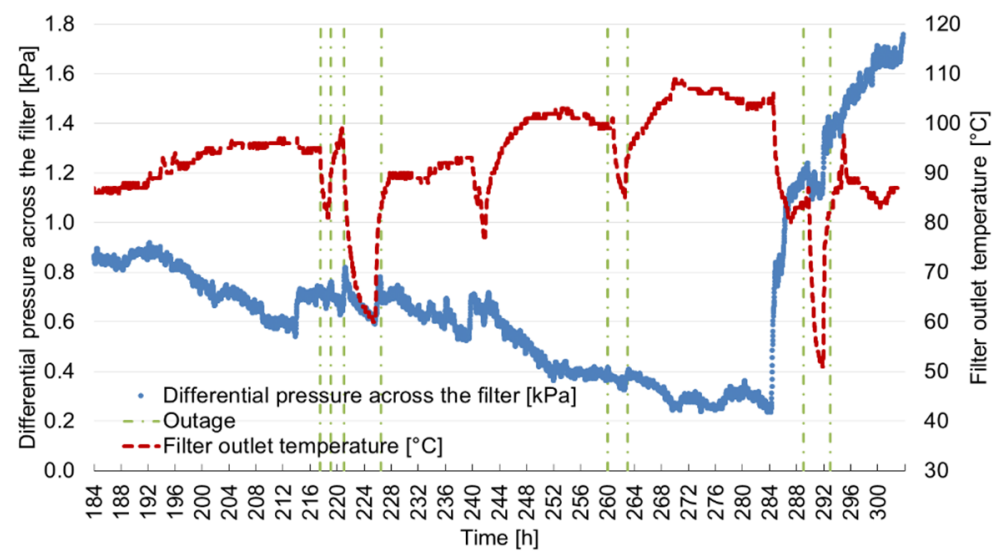

Figure 3: Impact of stream heating on $\Delta \mathrm{P}-\mathrm{GR}-\mathrm{SA}$.

There is a clear dependence of $\Delta \mathrm{P}$ on the gas temperature. The higher temperature helps to provide better filtering and lower $\Delta \mathrm{P}$, conversely, if the temperature of the stream suddenly decreases, the increase of $\Delta \mathrm{P}$ is rapid and significant. 
Another whole is consisted of 3 days measurement for NPK manufacture, see Figure 4. NPK fertilizer was extensively granulated by steam and water, which caused the filter saturation with water and increase of $\Delta \mathrm{P}$ to $2.2 \mathrm{kPa}$. The impact of gas stream heating on $\Delta \mathrm{P}$ was tested again. Heating of gas above $100^{\circ} \mathrm{C}$ decreased $\Delta \mathrm{P}$ back to $1.6 \mathrm{kPa}$. Finally, the last part of the test was performed with the GR-SA but without heating, $\Delta \mathrm{P}$ only slightly increases over time up to $2.1 \mathrm{kPa}$.

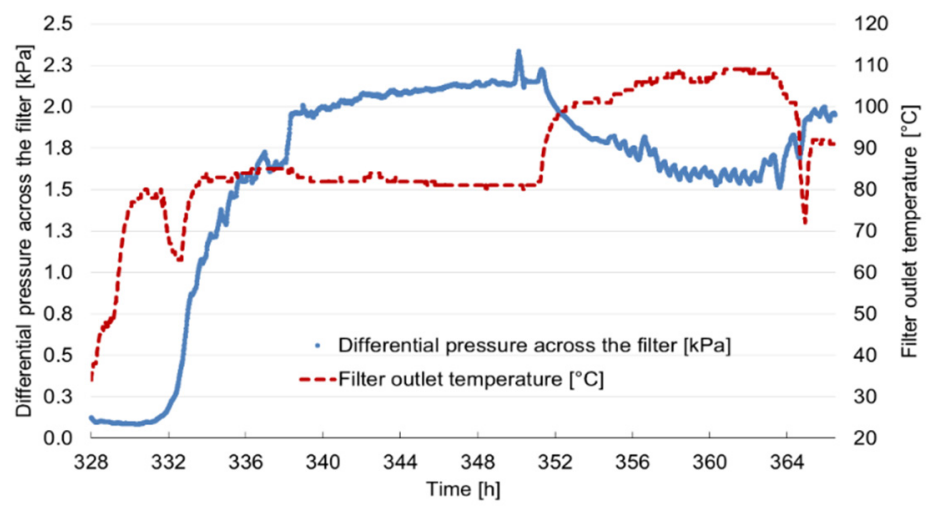

Figure 4: Pilot unit start-up - NPK.

From the course of long-term test, characteristic lines of pulse jet cleaning were selected, i.e. the time dependence of $\Delta \mathrm{P}$ between two consecutive cleaning pulses.

These lines also characterize the overall time course of the test, another result will be achieved, if for each condition and fertilizer, fresh filter bags were used. Lines in Figure 5 corresponds to relatively fresh new filter bags, lines in Figure 6 corresponds to more established filter bags.

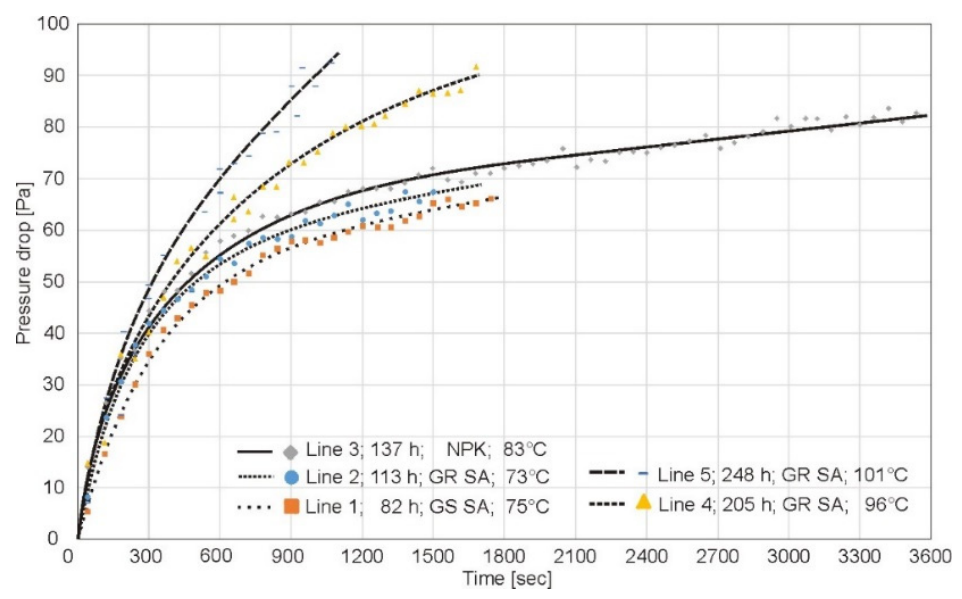

Figure 5: Characteristic trends of pulse jet cleaning - the time dependence of $\Delta \mathrm{P}$ for cleaning between two successive pulses. 


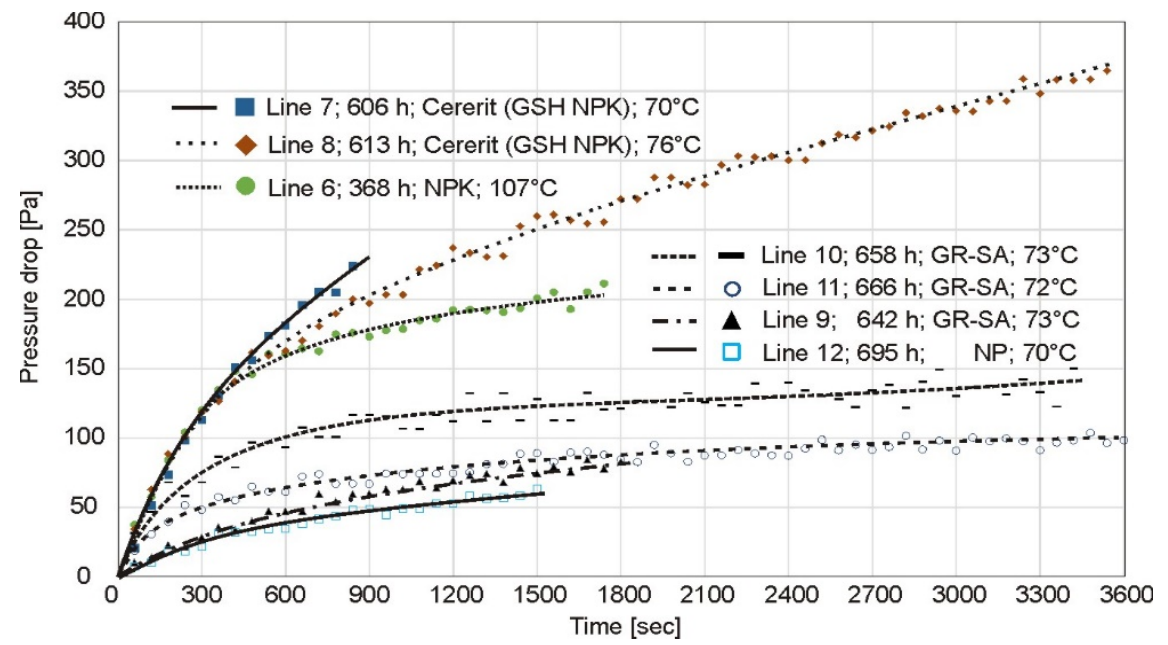

Figure 6: Characteristic trends of pulse jet cleaning - the time dependence of $\Delta \mathrm{P}$ for cleaning between two successive pulses - continued.

At the beginning of the test mostly granulated ammonium sulphate (GR-SA) has been made. When this product is made, only steam is used for the granulation (not steam-water combination as for NPK), therefore there is no more significant "clogging" of the filter, see Figure 5 lines 1 and 2 - lines looks very similar.

When switching to NPK granulate, slightly faster "clogging" of the filter was observed as can be seen in line 3. At the approximate time of $25 \mathrm{~min}$. (1500 s) the time dependence of $\Delta \mathrm{P}$ becomes linear.

Subsequently, the production returned to GR-SA with the temperature rise in the filter due to gas heating (lines 4 and 5). For these lines, increase of pressure loss comes more quickly, which corresponds to the separation of larger pieces of dust particles during cleaning pulse and thus increased pressure loss can be generated in shorter time after the pulse. Particles are probably making more dense cake, leading in quick rise of $\Delta \mathrm{P}$. Subsequent change of the product from the GRSA to NPK granulate led to even more significant increase in the pressure loss between pulses (Figure 6, line 6), the further increases in the differential pressures were caused by heating of the filter above $100^{\circ} \mathrm{C}$ and thus causing better cleaning of filtration surfaces (falling away of larger pieces of formed filter cake during pulse).

Line 6 could be also be negatively affected by excessive granulation by watersteam. After this point the filter was used without further preheat of inlet gas and thereby ordinary technology conditions were simulated at first for Cererit (GHS NPK) production, lines 7 and 8, was again observed the gradual clogging of the filter and removal of larger pieces of the filter cake.

In the subsequent production of GR-SA, the filter surface has been cleaned of newly deposited material only partially after each pulse. The cleaning pulse efficiency was not affected by the change of the pulse period or pulse pressure increase from 5 to 6 bar (lines 9-12). During prolonged operation (last hours of 
the test) filter material stayed partially clogged even after pulse, causing consequently reduction of the $\Delta \mathrm{P}$ between pulses up to $50 \%$. Major changes in the filter cleaning have been always a consequence of the production change or production outages.

\section{Conclusions}

34 days test of PM removal from air stream emerging from granulated fertilizers production in industrial plant was performed. Filter bags captured water which is contained the gas stream after granulation - about $10 \mathrm{~g}$ and $40 \mathrm{~g} \mathrm{H}_{2} \mathrm{O} / \mathrm{kg}$ of dry gas for GR-SA and NPK, respectively. Filtration of dust stream cannot be operated without increasing the temperature of gas above $100^{\circ} \mathrm{C}$. The best solution for fullscale unit seems to be the installation of a separate burner upstream of the filter and to keep filtration temperature above $80^{\circ} \mathrm{C}$ and $110^{\circ} \mathrm{C}$ for GR-SA (with no outages) and NPK respectively, during filtration and also outages. Average efficiency of PM capture by filter unit was $96 \%$. Outlet gas meets local emission limit for PM. Different cleaning pulses periods (7-60 min.) and pulse pressure (56 bars) had no impact on filter $\Delta \mathrm{P}$. More flat lines of time dependence of $\Delta \mathrm{P}$ between two consecutive cleaning pulses were observed with more difficult deposits already located on the filtration material and lower temperatures.

\section{Acknowledgements}

The results of this project NETME CENTRE PLUS (LO1202) were co-funded by the Ministry of Education, Youth and Sports within the support programme "National Sustainability Programme I". The authors also gratefully acknowledge financial support of the project CZ.1.07/2.3.00/30.0039 Excellent young researcher at BUT and the project Waste-to-Energy (WtE) Competence Centre no. TE02000236.

\section{References}

[1] Kim, K., Kabir, E. \& Kabir, S., A review on the human health impact of airborne particulate matter. Environ. Int., 74, pp. 136-143, 2015.

[2] Borgie, M., Ledoux, F., Verdin, A., Cazier, F., Greige, H., Shirali, P., Courcot, D. \& Dagher, Z., Genotoxic and epigenotoxic effects of fine particulate matter from rural and urban sites in Lebanon on human bronchial epithelial cells. Environ. Res., 136, pp. 352-362, 2015.

[3] Donaldson, K., Mills, N., Macnee, W., Robinson, S. \& Newby, D., Role of inflammation in cardiopulmonary health effects of PM. Toxicol. Appl. Pharmacol., 207(2), pp. 483-488, 2005.

[4] Morcos, V., Performance analysis of industrial bag filters to control particulate emissions. Energy, 21(1), pp. 9-14, 1996. 
[5] Saleem, M. \& Krammer, G., Optical in-situ measurement of filter cake height during bag filter plant operation. Powder Technol., 173(2), pp. 93106, 2007.

[6] Lupion, M., Alonso-Fariñas, B., Rodriguez-Galan, M. \& Navarrete, B., Modelling pressure drop evolution on high temperature filters. Chem. Eng. Process.: Process Intensif., 66, pp. 12-19, 2013.

[7] Saleem, M., Krammer, G., Khan, R. \& Tahir, M., Influence of operating parameters on cake formation in pilot scale pulse-jet bag filter. Powder Technol., 224, pp. 28-35, 2012.

[8] Simon, X., Chazelet, S., Thomas, D., Bémer, D. \& Régnier, R., Experimental study of pulse-jet cleaning of bag filters supported by rigid rings. Powder Technol., 172(2), pp. 67-81, 2007.

[9] Lupion, M., Rodriguez-Galan, M., Alonso-Fariñas, B. \& Gutierrez Ortiz, F., Investigation into the parameters of influence on dust cake porosity in hot gas filtration. Powder Technol., 264, pp. 592-598, 2014.

[10] Saleem, M. \& Krammer, G., Effect of filtration velocity and dust concentration on cake formation and filter operation in a pilot scale jet pulsed bag filter. J. Hazard. Mater., 144(3), pp. 677-681, 2007.

[11] Saleem, M., Krammer, G. \& Tahir, M., The effect of operating conditions on resistance parameters of filter media and limestone dust cake for uniformly loaded needle felts in a pilot scale test facility at ambient conditions. Powder Technol., 228, pp. 100-107, 2012.

[12] Simon, X., Bémer, D., Chazelet, S., Thomas, D. \& Régnier, R., Consequences of high transitory airflows generated by segmented pulse-jet cleaning of dust collector filter bags. Powder Technol., 201(1), pp. 37-48, 2010.

[13] Simon, X., Bémer, D., Chazelet, S. \& Thomas, D., Downstream particle puffs emitted during pulse-jet cleaning of a baghouse wood dust collector. Powder Technol., 261, pp. 61-70, 2014.

[14] VDI/DIN 3926, Part 1, Testing of cleanable filter media - standard test for the evaluation of cleanable filter media, VDI/DIN Manual Air Pollution Prevention, 6. Verein Deutscher Ingenieure.

[15] ASTM D 6830-02, Standard test method for characterizing the pressure drop and filtration performance of cleanable filter media, Book of Standards, 11.03. American Society for Testing and Materials.

[16] GB 12625, Technical requirements of fabric and bag for bag filter, National Standard of the People's Republic of China.

[17] JIS Z 8909-1, Testing methods of filter media for dust collection, Japanese Industrial Standard.

[18] ISO 11057:2011, Air quality - test method for filtration characterization of cleanable filter media, International Industrial Standard.

[19] Mao, N., Yao, Y.\& Kanaoka, C., Comparison of filtration performances of cleanable fabric filters measured by VDI and JIS testing rigs. Adv. Powder Technol., 17(1), pp. 85-97, 2006. 